\title{
Proceedings of the 127th Meeting of the Society of British Neurological Surgeons, Dublin, 5-9 September 1995
}

LOSS OF HETEROZYGOSITY IN SPORADIC CORTICAL DYSPLASIA FOR DNA MARKERS IN THE REGION OF THE TUBEROUS SCLEROSIS (TSC1) GENE ON CHROMOSOME 9Q34 M Farrell, A Greene, T Sepp, PS Mischel, HV Vinters. Beaumont Hospital, Dublin, Ireland, Cambridge University, UK and UCLA Medical Center, Los Angeles, CA, USA

Background-Neurohistological similarities between cortical dysplasia (CD) and tuberous sclerosis (TSC) have given rise to the hypothesis that $C D$ is a forme tuberous sclerosis of TSC. Hamartomas, including a cortical tuber, from cases of TSC show loss of heterozygosity (LOH) for DNA markers in the region of the TSC gene on chromosome 16p13.3.' Other TSC hamartomas show allele loss for DNA markers in the region of the TSC1 gene on chromosome $9 \mathrm{q}^{3}$. $^{2}$ These data are consistent with the hypothesis that both the TSC1 and TSC2 genes act as tumour or growth suppressors, according to Knudson's theory. On this basis, the lesions seen in TSC may occur occasionally in a patient who does not have TSC, as an isolated finding due to two somatic gene inactivity mutations. In some cases, the inactivating mutation may be large enough to remove genetic material in the region of the TSC gene, giving rise to $\mathrm{LOH}$.

Objectives-To determine if there were genetic similarities between CD and TSC.

Methods-DNA extracted from paraffinembedded normal brain and from CD brain obtained from three non-TSC patients during neocortical surgical resections for intractable epilepsy was analysed. Polymorphic dinucleotide repeat DNA markers were analysed by PCR, using normal DNA and DNA from $C D$ as templates. The DNA markers analysed spanned the region of the known TSC2 gene, and the as yet uncloned TSC1 gene.

Results-One of the three $\mathrm{CD}$ tissues showed LOH in the region of the TSC1 gene. No LOH was found in any of the tissues for markers flanking the TSC2 gene.

Conclusion-There is preliminary evidence that $C D$ may arise as a result of inactivation of both somatic alleles of a TSC gene, analogous to a somatic "localised" form of TSC (PSM and HVV are supported by NS 28383).

1 Green AJ, Smith M, Yates JR. Loss of heterozygosity on chromosome $16 \mathrm{p} 13.3$ in hamartomas from tuberous sclerosis patients. Native Genetics 1994;6:193-6.

2 Green AJ, Johnson PH, Yates JR. The tuberous sclerosis gene on chromosome $9 \mathrm{q} 34$ acts as a growth suppressor. Hum Mol Genet 1994;3:1833-4.

CYTOKINE EXPRESSION IN ANTERIOR PITUITARY ADENOMAS

LN Tripathy, B Mathew, SL Atkin, MC White. Department of Neurosurgery, Hull Royal Infirmary, Department of Medicine, University of Hull, Hull, UK

Objective-To investigate cytokine expression in human pituitary adenomas.
Design-Tumour tissue collected sequentially was examined blindly without prior knowledge of the clinical diagnosis, which was determined retrospectively.

Subjects-Tumour tissue was collected from 17 clinically confirmed patients with pituitary adenoma during their surgery.

Outcome measures-Determination of the presence or absence of cytokine expression in each of the tumours.

Results - IL8 was expressed in all tumours. TGF $\beta 1$, TGF $\beta 2$, and TGF $\beta 3$ were expressed in 16,11 , and 13 of the 17 adenomas respectively. IL2, IL5, and IL7 were not expressed in any tumour. Sporadic expression of IL $1 \alpha / \beta$, IL4, IL6, and TNF $\alpha / \beta$ occurred independently of the tumour type.

Conclusions-Pituitary adenomas express a wide profile of cytokines and an understanding of their overexpression or underexpression may lead to novel endocrine treatment options in the future.

\section{INVESTIGATION, MANAGEMENT, AND} TREATMENT OUTCOME IN NINE CHILDREN AND ADOLESCENTS WITH CUSHINGS' DISEASE, AFTER TRANSPHENOIDAL SURGERY

JS Norris, A Weber, AB Grossman, PN Plowman, GM Besser, MO Savage, F Afshar. Department of Neurosurgery, The Royal London Hospital, Whitechapel, London, UK

Cushings' syndrome in childhood is extremely rare and a proportion will have Cushings' disease as a cause. A total of 177 new cases of Cushings' syndrome were referred to this supraregional endocrine unit during the period from 1978 to 1993 , and only $12(6 \cdot 8 \%)$ were children. Nine $(5 \cdot 1 \%)$ of these (five boys, four girls; age range $7 \cdot 6-17 \cdot 8$ years) were found to have Cushings' disease. This constitutes $8 \cdot 2 \%$ of the overall experience of 110 cases (all ages) of Cushings' disease requiring surgery from 1984 to 1994.

Treatment modalities included surgery and pituitary radiotherapy. These were performed by the senior surgeon and radiotherapist in all cases. Six of the nine children required surgery alone, with the remaining three needing adjuvant radiotherapy. To date seven are completely cured, with two in remission. Cases of persisting Cushings' disease were all successfully treated by externa beam radiotherapy.

The results confirm that the services of a specialised paediatric neuroendocrine unit and an experienced neurosurgeon and radiotherapist offer these children the best chance of cure.

FLOW CYTOMETRIC EVALUATION AND KI67 LABELLING OF OLIGODENDROGLIOMAS: IS INTRAOPERATIVE ASSESSMENT OF PROLIFERATING TUMOUR A POSSIBILITY? K Seex, J Nicoll, P Stanton, R Rampling, G Cruickshank. Departments of Neurosurgery and Neuropathology, Institute Neurological Sciences, Glasgow, Department of Surgery,
Glasgow Royal Infirmary, and Beatson Oncology Unit, Western Infirmary, Glasgow, UK

Aims-The improved excision of focal brain tumours is associated with increased survival. Morphological imaging does not allow this objective to be realised, as such techniques do not allow imaging of the true proliferative zone. It is possible that real time flow cytometry coupled to the product of the CUSA might allow improved excision by directed aspiration of growing tumour. This study sets out to investigate $S$ phase fraction (SpF) DNA analysis as a method of identifying proliferating tumour by comparison of $\mathrm{SpF}$ analysis, with $\mathrm{Ki} 67$ indices from a retrospective sample of oligodendrogliomas.

Subjects-Fifty patients producing 63 biopsies (1977-90)

Methods-Original histology was reviewed and the grading updated. Ki67 immunohistochemistry was performed, and the labelling index (LI) evaluated by a stratified counting technique, centred on the most active tissue areas. Flow cytometric profiles were performed, and ploidy and (SpF) calculated.

Results-LI and flow cytometry correlated unreliably with the histological grade, but better with survival. The LI (median 3.5\% $0-35 \%$ ) correlated well with the $\mathrm{SpF}$ (median $5 \cdot 8 \% \quad 1 \cdot 4-27 \%$ ). Flow cytometry showed a $53 \%$ diploid population and a $47 \%$ aneuploid/tetraploid population.

Conclusions - In oligodendrogliomas conventional histology is poor at predicting proliferative potential. The correlation between $\mathrm{Ki67}, \mathrm{SpF}$ and outcome suggests that realtime flow cytometric analysis might allow a more directed and more effective approach to the operative removal of proliferating tumour.

ENDOSCOPIC MANAGEMENT OF PINEAL REGION TUMOURS

HB Coakham, I Pople, DR Sandeman. Department of Neurosurgery, Frenchay Hospital, Bristol, UK

Objective-The wide variety of pineal region tumours require different management strategies which are best determined by biopsy. Early treatment of hydrocephalus is usually necessary. A method of endoscopic biopsy and third ventriculostomy has been developed which achieves both these objectives.

Design and subjects-Fifteen patients presented with obstructive hydrocephalus due to pineal masses between 1983 and 1995 . Via a coronal burr hole a rigid solid lens neuroendoscope was passed freehand and a biopsy taken. Recently a flexible fibrescope was also used. Third ventriculostomy was performed using diathermy and a Forgharty balloon catheter.

Results-Histology obtained in all cases: pineoblastoma two, pineocytoma two, germinoma four, teratoma four, astrocytoma one, carcinoma two. Biopsy was misleading in one case. Ventriculostomy was successful 
in 5/5 cases. Appropriate definitive treatment was then carried out according to current protocols.

Conclusions-The neuroendoscope is a valuable instrument in the initial management of pineal tumours. The combined use of rigid and flexible endoscopes through a common sheath is our current recommendation.

1 Fukushima $\mathrm{T}$, Ishijima $\mathrm{B}$, Hirakawa $\mathrm{K}$, Hakamura N, Sano K. Ventriculofiberscope: a new technique for endoscopic diagnosis a new technique for endoscopic diagn

2 Griffith HB. Techniques of fontanelle and persutural ventriculoscopy and endoscopic ventricular surgery in infants with
hydrocephalus. Childs Brain 1975;1:359-93.

AN AUDIT OF INTRINSIC BRAIN STEM

TUMOURS PRESENTING AT GREAT ORMOND STREET HOSPITAL FOR CHILDREN BETWEEN 1980 AND 1990

B Chitnavis, WFJ Harkness, RD Hayward. Great Ormond Street Hospital for Children, Great Ormond Street, London, UK

Objective-To analyse the presentation, pathology and long term prognosis of brain stem tumours in children.

Methods-Thirty paediatric patients with brain stem tumours presenting at Great Ormond Street Hospital between 1980 and 1990 were reviewed. The factors evaluated included age at presentation, duration of symptoms before presentation, examination findings, radiology, operative intervention, history, adjuvant treatments, and duration of survival after diagnosis.

Results - The study was a retrospective analysis of 30 patients (19 girls and 11 boys) with brain stem tumours, aged 1 week to 14 years (mean 5 years). Symptoms manifested a mean of five months before diagnosis. The site of involvement was pontine in 20 patients, midbrain in four patients, medullary in three patients, and extensive in two patients. MRI was available in 24 patients and CT in all patients. Histology was obtained in 11 patients; two at surgery to debulk the tumour, eight through burr hole biopsies, and one through cytological analysis of CSF. Four were malignant gliomas, six were low grade gliomas, and one a PNET. Twenty six patients received radiotherapy, six patients were given chemotherapy in addition, four patients received neither. Eight patients required shunting for hydrocephalus. Median survival time after diagnosis was nine months; six patients remain alive.

Conclusion-The prognosis for intrinsic brain stem tumours remains poor with six of 30 patients surviving more than five years. Future improvements are unlikely to be surgical and work continues to find an effective chemotherapeutic regime to accompany radiotherapy.

THE HAEMODYNAMIC EFFECT OF VASOSPASM ON THE CIRCLE OF WILLIS

JG Rowe, A Thomas, A Molyneux, JV Byrne, CBT Adams, B Rajagopalan. MRC Spectroscopy Unit, John Radcliffe Hospital and Departments of Neurosurgery and Neuroradiology, Radcliffe Infirmary, Oxford, UK

Objective-To investigate how proximal vasospasm affects cerebrovascular resistance.
Methods-Mean arterial pressures (MAP) were measured around the circle of Willis, in patients undergoing endovascular treatmen of aneurysms. Seven patients had vasospasm, 20 did not. Values are mean \pm SD.

Results-Without vasospasm pressure gradients were small. The MAP at the anterior communicating artery (ACoA) origin was 97 (3) $\%$ of the extracranial carotid, and at the middle cerebral artery (MCA) bifurcation $94(7) \%$. Without vasospasm $<5 \%$ of the cerebrovascular resistance arose at the circle of Willis. Pressure gradients increased with proximal vasospasm, $82(6) \%$ and $74(10) \%$ of extracranial carotid MAP being transmitted to the ACoA origin and MCA bifurcation. On average threequarters of the resistance still arose distally, and pressures measured at these points $(65$ (13) $\mathrm{mm} \mathrm{Hg}$ and $57(18) \mathrm{mm} \mathrm{Hg}$ respectively) were above the lower limit of autoregulation, suggesting that proximal vasospasm alone was insufficient to compromise blood flow. As flow decreased less than vessel lumenal area, transcranial Doppler velocities should be increased. This was confirmed in four patients

Conclusions-The modest effect of proximal vasospasm on cerebrovascular resistance has implications for the development of ischaemia after subarachnoid haemorrhage, and for the use of angiography in guiding treatments for vasospasm, such as angioplasty.

ARTERIOVENOUS MALFORMATIONS IN

CRITICAL AREAS OF THE BRAIN:

MICRONEUROSURGICAL EXCISION: THE GOLD STANDARD IN CURRENT TREATMENT? SA O'Laoire. Department of Neurosurgery, Mater Private Hospital, Dublin 7, Ireland

Materials and methods-Fifty six patients who had AVMs in eloquent areas of cortex or deep brain, or were of large multiterritorial size were excised using microsurgical techniques between June 1981 and November 1989. Single stage surgery was used in 44 cases, and deliberate surgical staging in 10 cases. In four cases routine postoperative angiography disclosed residual AVM, and further treatment was surgical in two cases and focused radiation in two Presentation followed haemorrhage in 41 cases $(73 \%)$, progressive neurological defici (PND) in nine cases (16\%), and epilepsy in six cases $(11 \%)$

Results-Forty three patients made a good recovery $(77 \%)$, seven were fair $(13 \%)$ three had a poor result $(5 \%)$, and three died (5\%). Three patients developed a new or increased deficit after surgery (5\%), and seven of nine patients who had epilepsy and who had not bled are free of epilepsy $(78 \%)$ No new cases of long term epilepsy have occurred after surgery (minimum follow up is now five years)

Conclusions-Microsurgical excision of cerebral AVMs even in critical areas of the brain has a far better outcome than the natural history of conservatively treated lesions. Surgery should be considered not only after haemorrhage, but also in cases presenting with PND or epilepsy. The non-surgical treatments of these lesions require very critical assessment in the light of the results of modern microneurosurgery.
ENDOVASCULAR EMBOLISATION OF INTRACRANIAL ARTERIOVENOUS MALFORMATIONS

P Brennan, AJ O'Dwyer, JP Phillips, J Toland. Department of Neuroradiology and Neurosurgery, Beaumont Hospital, Dublin, Ireland

Objective-To clarify the role of endovascular treatment of intracranial arteriovenous malformations (AVMs)

Design-A retrospective review was performed of the patients who underwent endovascular treatment of AVMs.

Subjects-Eighteen patients were included within an 18 month period from January 1994 to June 1995. Follow up angiography and clinical review were performed in al cases.

Results-Four AVMs were completely obliterated, 14 were partially treated, 10 were reduced significantly in size and four were considered failures. Subsequently four patients underwent curative surgery, one radiosurgery; two others await radiosurgery, and three await further treatment. Two had transient neurological deficits after treatment; no patient had rebleeding, and on patient had a permanent neurological deficit.

Conclusions-Endovascular embolisation has an important supportive role in treating AVMs.

1 For AJ, Pelz DM, Lee DH. Arteriovenous malformations of the brain. Recent results of endovascular therapy. Radiology 1990;177: 51-7.

2 Dawson RC, Tarr RW, Hecht ST, Jungress CA, Lundsford LD, Coffey R, Horton JA Treatment of arteriovenous malformations of the brain with combined embolisation and stereotactic radiosurgery; results after 1 and

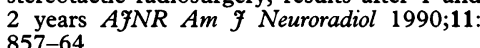

FACTORS IMPLICATED IN DEATHS FROM SUBARACHNOID HAEMORRHAGE: ARE THEY AVOIDABLE?

PJA Hutchinson, H Seeley, PJ Kirkpatrick. Academic Neurosurgical Unit, Addenbrooke's Hospital, Hills Road, Cambridge, UK

Introduction-Although causes of death from subarachnoid haemorrhage (SAH) are multifactorial, some are potentially avoidable. In addition, poor grading (often considered a contraindication for transfer to neurosurgical departments) in patients may be due to correctable factors. By auditing patients who have died from SAH we have attempted to explore these possibilities.

Methods-The records and CT of 100 patients (mean age 54.8) who died from SAH were derived from two district general hospitals and the neurosurgical department (NSD).

Results-General: Eighteen of the patients were considered unsalvagable (WFNS Grade 5, pupils fixed). In the remainder, 57 were good grade (WFNS 1-3) of which 38 $(67 \%)$ died of a rebleed (mean day $12 \cdot 8$ ). Of 25 poor grade patients, hydrocephalus was identified in seven $(28 \%)$. In addition, poor resuscitation (seizure control and inadequate intravenous fluids) were considered possible contributing factors in $13(52 \%)$ cases. District hospitals: Those transferred arrived in the neurosurgical department on (mean) day $2 \cdot 6$. Out of 26 deaths (10 good grade) the NSD was not contacted in 13 cases (six good grade). Of the eight poor grade patients correctable factors were identified in four $(50 \%)$ 
Conclusion-Rebleeding was the main cause of death in all grade patients. In addition, possible reversible factors were identified which prompt a more active neurosurgical role in the management of poor grade patients.

THE MANAGEMENT OF LESIONS OF THE DISTAL EXTRACRANIAL INTERNAL CAROTID ARTERY

N Patel, RJ Nelson, T Lewis, M Morse. Departments of Neurosurgery, Neuroradiology, and Radiology, Frenchay Hospital, Bristol, UK

Objective-To present the surgical approach to lesions of the distal extracranial internal carotid artery and to describe the optimal multidisciplinary management of these lesions.

Design-A prospective study of patients admitted consecutively over a two year period with angiographically confirmed lesions of the suprahyoid segment of the extracranial internal carotid artery.

Patients-Ten patients (six men, four women; mean age 54) with acute or transient cerebral ischaemia due to several diseases including atypical atherosclerosis, post-traumatic, iatrogenic, or spontaneous arterial dissection, and aneurysm formation.

Interventions - A combination of open surgical techniques including endarterectomy, patch angioplasty, and saphenous vein bypass grafting and endovascular techniques including carotid stenting and balloon angioplasty.

Outcome-The management of the arterial lesion and long term outcome in seven patients has been good. One patient had a fatal postoperative myocardial infarction, one patient developed fatal postoperative cerebral oedema, and one patient has had a recurrence of a carotid dissection after stenting.

Conclusions-Lesions of the distal extracranial carotid artery are unusual and are technically demanding for both the surgeon and interventional radiologist. With careful assessment and planning good results may be obtained in most patients.

IDIOPATHIC SYRINGOMYELIA ASSOCIATED

WITH FOCAL SUBARACHNOID

CONDENSATIONS MAKING WEBS

CL Mallucci, R Stacey, J Miles, B Williams. Midland Centre for Neurosurgery, Birmingham, and Walton Centre for Neurosurgery, Liverpool, UK

Objective-Ten patients with symptomatic syringomyelia without commonly recognised predisposing factors are reported. They have been found to have a focal area of arachnoiditis forming webs, pouches or cysts, and with blockage of the normal CSF flow.

Patients-Eight men and two women (average age 47 years). All had preoperative MRI evidence of syringomyelia of whom three had appearances suggestive of webs. Myelography in eight showed subarachnoid hold up of contrast from below compatible with subarachnoid webs.

Results-Eight patients had laminectomies and division of the obstructing arachnoid webs (one cyst) and the dura left widely open. Five of these had immediate good improvement in symptoms and three had only mild improvement. Two patients had shunting procedures (syringosubarachnoid and syringopleural), and both were immediately worse. Delayed follow up was available in nine patients (average two years), in which two patients had recurrence of symptoms. Postoperative MRI showed collapse of the syrinx in eight of nine patients.

Conclusions-Patients with idiopathic syringomyelia should be investigated for meningeal webs. The treatment of choice is laminectomy and excision of the obstructing arachnoid condensations so as to re-establish normal CSF flow and eliminate the filling mechanism. Their aetiology is unknown and early results of surgery seem good.

FAMILIAL CAVERNOUS MALFORMATIONS RJ Stacey, G Findlay, RV Jeffreys, P Humphrey, TP Enevoldson. Walton Centre for Neurology and Neurosurgery, Liverpool, UK

The availability of MRI has greatly increased the detection of cavernous malformation of the CNS in both symptomatic and asymptomatic patients. This has led to the realisation that, in cases where more than one cavernous malformation is present, there may be a familial component to the disease. These lesions may also be responsible for previously unexplained neurologica events or may even have been previously incorrectly diagnosed. A family, spanning three generations, is reported, in which at least eight members are affected with an autosomal dominant pattern of inheritance. Each patient presented independently with neurological complications. To date other asymptomatic family members have refused to be screened. In all cases multiple cerebral cavernomas were identified. In addition, in one case, an associated spinal cavernoma requiring surgery was also seen In four of the subjects the diagnosis was confirmed retrospectively only with the advent of MRI. In one patient a diagnosis of low grade glioma had previously been made. Only one of the patients has undergone surgery, with removal of two cerebral and one spinal cavernoma. A review of the literature shows this to be the largest series reported in a single family.

VERTEBROBASILAR ANEURYSMS: AN ANALYSIS OF 60 CASES

PV Marks, SA Ross. The General Infirmary, Leeds, UK

The results of management of 60 consecutive vertebrobasilar aneurysms over a six year period have been analysed. Aneurysms were found at the following sites: basilar bifurcation (30), posterior inferior cerebellar artery (nine), superior cerebellar artery (six), posterior cerebral arteries (seven), basilar trunk (three), anterior inferior cerebellar artery (two), vertebral artery (two), and basilar origin (one).

Ninety per cent of patients presented with subarachnoid haemorrhage but in several cases, the posterior circulation aneurysm was not responsible for the bleed and was therefore treated electively. A variety of surgical approaches were invoked including combined maxillofacial access procedures and the transoral transclival route. Three aneurysms were considered inoperable and two were subsequently treated by interventional radiology. Four deaths occurred in the postoperative period and two patients who were initially grades III and IV on the WFNS scale had poor outcomes. The remaining patients had good or excellent outcomes.
LUMBAR DIASTEMATOMYELIA: A MODEL FOR THE NEUROSURGICAL MANAGEMENT OF ALL TYPES OF OCCULT SPINAL DYSRAPHISM? RD Hayward, WFJ Harkness, U Andar. Great Ormond Street Hospital for Children, Great Ormond Street, London, UK

Objectives-To study the type and incidence of neurological, orthopaedic, and urological problems after both prophylactic surgery and surgery for progressive symptoms in children with lumbar diastematomyelia.

Methods-A retrospective review of patients seen at this institution over a 20 year period with diastematomyelia in the lumbar region but no evidence of other dysraphic abnormalities.

Results-Forty four cases out of a total of 84 fulfilled the entry criteria. The female/ male ratio was $2: 1$. Of the 33 patients operated on with no evidence of any progressive clinical problems, only one showed any evidence of deterioration during a follow up period that ranged from 1.3 to 17 years. Of 10 patients operated on because of progressive neurological, orthopaedic, and/or urological problems (average age at surgery 6.8 years) three improved whereas the remainder showed no evidence of further deterioration over a follow up period that averaged 5.7 years.

Conclusion-This study of a uniform cohort of patients with occult spinal dysraphism suggests that their clinical problems can be divided into two groups- "true" deterioration (defined as the loss of a previously normal function) and those due to the clinical emergence of abnormalities (usually at around 2 years of age) which had always been present but previously disguised by the immaturity of the nervous system. This model is helpful in the analysis of the results of surgery (prophylactic and symptomatic) for other forms of occult spinal dysraphism, such as the lipomeningoceles.

THORACIC DISC HERMIATION:

RE-EVALUATION OF THE LATERAL

POSTERIOR (HEMILAMINECTOMY AND

MICRODISCECTOMY) APPROACH

IH Chaudhry, K Saeed, C Marks, TF

Buckley. Neurosurgical Department, Cork

University Hospital, Cork, Ireland

Objectives-To assess the value and safety of the lateral-posterior (hemilaminectomy and microdiscectomy) approach to herniated thoracic discs.

Design-Retrospective study of 17 patients operated on in the unit from 1978 to May 1995. Follow up varied from four months to 17 years.

Subjects-There were 17 patients (6 men,

11 women) aged 31 to 61 years.

Outcome measures-Pre and postoperative neurological status were compared.

Results-Eleven patients made excellent or good recoveries, four were fair, one remained unchanged, and one became worse.

Conclusions-A posterior approach with hemilaminectomy and microdiscectomy is a safe, effective, cost efficient, and less traumatic procedure for thoracic disc herniation.

TETHERED CORD SYNDROME: RECENT

CLINICAL EXPERIENCE

S Sharif, P Brennan, C Marks, D Allcutt.

Departments of Neurosurgery and Neuroradiology, Beaumont Hospital, Cork University Hospital, Dublin, Ireland

"Tethered cord syndrome" is a controversial 
condition which may be due to fixation and stretching of the spinal cord by intradural or extradural elements. The current management and its results are controversial. Thirty seven consecutive patients who were treated surgically by two surgeons were reviewed. The mean age at presentation was 10 years (24 girls and 13 boys). Main presenting complaints were back and leg pain, foot and spinal deformities, motor and sensory deficits, and cutaneous manifestation of dysraphism. Average duration between onset of symptoms and surgery was 35 months and $86 \%$ reported deterioration of symptoms, 32 patients had MRI and five had myelograms. Indications for surgery were progressive neurological deterioration, primary prophylactic surgery or as a preliminary to corrective scoliosis surgery, and nine patients had had previous spinal surgery. The cord was untethered in 31 patients and the filum terminale was divided in 16 patients. There were no serious complications, two patients had a CSF leak which was repaired. Adequate postoperative follow up was available in 36 patients, of which $63 \%$ subjectively improved and $14 \%$ showed improved signs. There was no deterioration in neurology in any patient. Our series suggests that release of the cord in patients with tethered cord syndrome may improve or arrest progression of neurological deterioration. Thus close follow up and consideration of surgery for patients who develop signs of a tethered cord is recommended.

COLOUR DOPPLER IMAGING IN THE INVESTIGATION OF SHUNT FUNCTION

S Sgouros, P John, AR Walsh, AD Hockley. Childrens Hospital, Birmingham, UK

Objective-To investigate the value of Doppler sonography in detecting flow through ventriculoperitoneal (V-P) shunts.

Design - The observation of the normally invisible CSF flow from the peritoneal end of a V-P shunt during a conventional abdominal ultrasound examination in one of our patients led us to try colour Doppler imaging, using a $10 \mathrm{MHz}$ linear array transducer, which performed spectral and colour coded Doppler sonography. Further in vitro studies were performed with a simulated shunt/ventricular system model, to explore the limitations of the technique.

Patients-Seventeen patients with V-P shunts, aged 3 months to 12 years were insonated. Twenty examinations were performed because two patients had repeated examinations before and after shunt revision.

Results-In 13 examinations (65\%) CSF flow was identified through the shunt tube. Flow velocities between $5-7 \mathrm{~cm} / \mathrm{s}$ were measured. No flow was seen in seven examinations $(35 \%)$. Of these, three examinations (15\%) were performed before revisions for blocked shunt. In vitro studies demonstrated that although clear CSF is not ultrasonically visible, the presence of particulate matter, such as choroid plexus debris, can generate a satisfactory Doppler signal with the probe insonating over the length of the tubing. In the presence of clear CSF, turbulence generated at junction points of the shunt system or at the exit of the peritoneal tube can be visualised well with Doppler sonography, presumably due to generation of microbubbles.

Conclusions-This preliminary report suggests that colour Doppler imaging may prove helpful in demonstrating flow through shunts, although at this stage there would seem to be a considerable number of false negative results. Further improvements with aquisition techniques could decrease the incidence of false negatives, allow differentiation of constant or intermittent flow through functioning shunts, and identify shunt independent patients. If the method becomes established, the clinical implications in the management of shunt obstruction are obvious.

THE NON-SURGICAL MANAGEMENT OF CSF SHUNT INFECTIONS

EM Brown, EM Jones. Department of Medical Microbiology, Frenchay Hospital, Bristol, UK

Treating shunt infections with antibiotics alone has consistently yielded cure rates which have been significantly lower than those achieved with a combination of shunt removal and antibiotics. A critical evaluation of how patients have previously been managed conservatively disclosed several explanations for these poor results: inappropriate antibiotics; inadequate dosages; and, most importantly, administration by routes which failed to produce therapeutic concentrations in the CSF. This knowledge was used to devise a regimen which would represent optimal non-surgical therapy of shunt infections caused by Gram positive cocci, the predominant pathogens. Vancomycin, instilled into the ventricles through an Ommaya reservoir, combined with systemically administered rifampicin and, in selected cases, intraventricular gentamicin, all for two weeks, was expected to yield the highest response rates. To date, 24 episodes of shunt infection in 22 patients have been treated; three were managed, at least in part, on an outpatient basis. Clinical and bacteriological cure rates were achieved in 20 of the 24 (83\%) episodes, including all 15 caused by coagulase negative Staphylococci; four of the five infections caused by staphylococcus aureus failed to respond. After follow up periods of between six months and more than eight years, there were no relapses in patients who were cured, no deaths, and no adverse events attributable to treatment. These results suggest that treatment of shunt infections caused by bacteria other than $S$ aureus according to this regimen yields cure rates which are comparable with those achieved with conventional management.

CSF SHUNT INFECTIONS: A REVIEW

R Zafar, S Sharif, D Rawluk, E McNamara, E Smyth. Departments of Neurosurgery and Microbiology, Beaumont Hospital, Dublin, Ireland

Cerebrospinal fluid shunt infection remains a difficult management problem and in the recent past there have been very little data considering this issue. This study was undertaken to review the incidence, aetiological agents, clinical presentation, and management protocol to facilitate further efforts to reduce their occurrence in the future. Microbiological data, theatre and patient case records were reviewed retrospectively, and 534 operations for shunt insertion were carried out between January 1992 and March 1995. There were the 45 cases of microbiologically proved CSF shunt infections thus yielding an incidence rate of $8 \cdot 4 \%$. Mean age of subjects was $29 \cdot 6$ (range 2 to 72 ) years, $56.5 \%$ being males, and
95.5\% of infective episodes involved ventriculoperitoneal shunts. The major indication for insertion being hydrocephalus in association with spina bifida. Mean number of previous shunt revisions in these was two (range 0 to 7 ), common presenting features were pyrexia, leucocytosis, vomiting, and headache. Overt wound infections were observed in $20 \%$. The aetiological agents being Staphylococcus aureus in $55.5 \%$ and coagulase negative Staphylococcus in $37.7 \%$ of these episodes. The use of external ventricular drainage was employed in $60 \%$ and eventually shunts were revised in $86.6 \%$. Antibiotics were used in $91 \%$ of cases, $55 \%$ being intraventricular. Mean stay in hospital was 17 (range 9 to 107) days. The use of intensive care facilities was employed in $15.5 \%$ of cases, $8.8 \%$ requiring ventilatory support for a mean period of 48 hours. It is therefore considered that much more effort needs to be directed towards prevention of CSF shunt infection, given the problems of antibiotic therapy, if the costs incurred by these potentially lethal complications are to be limited.

IN VIVO STUDY OF CODMAN MICROSENSOR INTRACRANIAL PRESSURE CATHETERS WP Gray, M Gardner, J Gill, F Iannotti. Department of Neurological Sciences, Wessex Neurological Centre, Southampton General Hospital, Southampton, UK

Objective-To measure the accuracy of a newly developed intracranial pressure (ICP) catheter in which a microsensor is located at the tip.

Design-All patients had a standard right frontal fluid filled subdural catheter system inserted. In addition, a microsensor catheter was inserted within the fluid filled subdural catheter. Finally a separate microsensor catheter was inserted into the brain parenchyma. A computerised monitoring system was used to simultaneously record all three ICPs. Microsensor drift was recorded at explant.

Patients-Eleven patients requiring ICP monitoring.

Results-The tissue sensor became dislodged and traumatised in two patients. This left nine patients with 36000 valid simultaneous recordings. Tissue ICP measured by the microsensor catheter was higher than the subdural fluid filled catheter by $2.8 \mathrm{~mm} \mathrm{Hg}(P<0.001)$ and the subdural microsensor catheter by $1.5 \mathrm{~mm} \mathrm{Hg}(\mathrm{P}<$ $0 \cdot 001)$. The tissue microsensor catheter gave a superior quality recording with a mean amplitude of $5.5 \mathrm{~mm} \mathrm{Hg}$ compared with the subdural sensor $(4.4 \mathrm{~mm} \mathrm{Hg})$ and the subdural fluid catheter $(3 \mathrm{~mm} \mathrm{Hg}$ ). Mean sensor drift was $<1 \mathrm{~mm} \mathrm{Hg}$.

Conclusions-Microsensor tipped catheters record ICP accurately and tissue measurements yield a superior recording.

TREATMENT OF HYDROCEPHALUS SHUNT INFECTIONS: BSAC WORKING PARTY RECOMMENDATIONS

R Bayston, J De Louvois, E Brown, A Hedges, $\mathbf{R}$ Johnston, $\mathbf{P}$ Lees. University Department of Microbiology (Infectious Diseases), City Hospital, Nottingham, UK

Though the incidence of shunt infections has fallen in recent years, they are still a major problem in the control of hydrocephalus. The incidence is highest in babies, and reasons for this have been proposed. The commonest causative organisms are 
the coagulase negative Staphylococci. Early reports showed clearly that regimens in use for other staphylococcal infections were ineffective, and the reasons for this are pharmacological (related to drug penetration into the CNS) and microbiological (factors produced by the organisms during infection). All reports of attempts to treat shunt infections without removal of the device have shown disappointing results. ${ }^{1}$ Vancomycin is the antimicrobial of choice for treatment of shunt infections due to Gram positive bacteria, and is both safe and effective when administered intraventricularly. ${ }^{2}$ Its activity is enhanced by the addition of rifampicin. The recommendation of the working party is that, for Gram positive infections, the shunt should be removed and external ventricular drainage instituted; and that intraventricular vancomycin and either oral or intravenous rifampicin should be given. Recent studies however, suggest that this regimen might be successful without shunt removal in some cases and the recommendation may need to be revised. In those patients with a shunt who develop community acquired meningitis due to haemophilus, pneumococcus, or meningococcus, shunt removal is not necessary. For infections due to Gram negative bacilli or candida, the working party recommends immediate shunt removal and appropriate antimicrobial chemotherapy.

1 James HE, Walsh JW, Wilson HD, Connor JD, Bean JR, Tibbs PA. Prospective randomized Bean JR, Tibbs PA. Prospective Condomized infection. Neurosurgery 1980;7:459-63.

infection. Neu

Bayston R, Hart CA, Barnicoat M Intraventricular vancomycin in the treatmen of ventriculitis associated with cerebrospinal fluid shunting and drainage. $f$ Neurol Neurosurg Psychiatry 1987;50:1419-23.

ADULT HEAD INJURIES IN EUROPEAN CENTRES: A PILOT STUDY

GM Teasdale, G Murray on behalf of the European Brain Injury Consortium. University Department of Neurosurgery, Institute of Neurological Sciences, Glasgow, UK

Objective-To determine the acceptability of a "core data set" of observations on acute head injuries and the feasibility of using this to obtain information in collaborative research in European centres.

Design-A two page proforma, containing 60 items of information on demography, clinical features, investigation, management, and early outcome was devised. Centres throughout Europe were invited to submit data on moderate and severe head injured patients admitted from 1 February to 30 April 1995.

Outcome measures-The number of centres responding, the number of patients reported, and quality and credibility of data.

Results-Reports on more than 750 patients have been received from 61 centres. The conformity of data has been high but some ambiguities have been identified. The median age was $37,73 \%$ were men and $50 \%$ were road traffic accidents. The median time from injury to neurosurgical admission was 2.92 hours, and $75 \%$ had a severe injury. Clinical data "prehospital" were available in $60 \%$ of cases; when admitted to neurosurgery, more than a third had some aspect of the Glasgow coma scale untestable. Results of CT according to the Traumatic Coma Databank categories were: I, $12 \%$; II, $27 \%$; III, $12 \%$; IV, $3 \%$; $44 \%$ had a "mass" lesion evacuated.

Conclusions-The core data proformas were widely accepted; a large number of patients were reported in a brief period; the data were of high quality and credibility and provide a valuable basis for planning further research.

'H MAGNETIC RESONANCE SPECTROSCOPY OF ACUTE HEAD INJURY

D Oluoch-Olunya, B Condon, D Hadley, A Wagstaff, GM Teasdale. Department of Neurosurgery, Beaumont Hospital, Dublin, Ireland, and Departments of Clinical Physics, Neuroanaesthesia, and Neurosurgery, Institute of Neurological Sciences, Glasgow, UK

Introduction-Secondary ischaemic brain damage is exceedingly common in fatal head injuries, but when this occurs in life is unclear. Cerebral blood flow studies have shown hypoperfusion, particularly early after head injury, but confirmation of ischaemic metabolic changes has been difficult Previous ${ }^{31} \mathrm{P}$ magnetic resonance spectroscopy (MRS), showed a tendency to intracellular alkalosis. ${ }^{1}$ Four cases studied, within 20 hours of injury to seek lactate as an index of anaerobic glycolysis.

Methods-The patients were ventilated to a $\mathrm{PaCO}_{2}$ of $4.33(1 \cdot 1) \mathrm{kPa}$ and monitoring including ICP with MR compatible equipment. No untoward events occurred during $M R$ investigation performed with a Siemens 1.5 Tesla system. Spin echo (SE) $1500 / 135$ and SE1500/270 ${ }^{1} \mathrm{H}$ spectra were collected from two volumes of interest (VOI) identified by imaging (1) adjacent to and (2) remote from maximum focal damage consisting of contusions, or acute subdural haematoma. Three of the patients were imaged postoperatively.

Results-Lactate was identified as being present if a negative peak at the correct chemical shift position changed from negative on the SE1500/135 to positive on the SE1500/270. Lactate was detectable in all four VOIs adjacent to the focal lesion; two of which were greater than the $\mathrm{N}$-acetylaspartate, choline or creatine peak areas.

There was a smaller lactate peak in two of the remote regions.

Conclusion-Intracellular lactacidosis has now been demonstrated in the first hours after head injury in humans. Further studies will explore its pathophysiological and therapeutic implications.

1 Rango M, Lenkinski RE, Alves WM, Gennarelli TA. Brain pH in head injury: an image-guided ${ }^{31} \mathrm{P}$ magnetic resonance spectroscopy study. Ann Neurol 1990;28:661-7.

THE AXONAL CYTOSKELETON IS ALTERED EARLY IN DIFFUSE HEAD INJURY IN HUMANS MO Fitzpatrick, EA Irving, DI Graham, D Dewar. Wellcome Surgical Institute and the Institute of Neurological Sciences, Southern General Hospital, Glasgow, UK

Objective-To study the cytoskeleton in diffuse axonal injury and to detect specific markers of axonal injury.

Design-Comparison of the immunoreactivity of the microtubule component of the cytoskeleton in diffuse axonal injury and normal brain tissue. Cases are age and survival time matched.

Specimens-Human postmortem brain tissue with the neuropathological diagnosis of diffuse axonal injury $(n=11)$ and normal brain tissue $(n=8)$.

Outcome measures-Monoclonal antibody immunohistochemical staining.

Results-There are disturbances in the cytoskeleton in diffuse axonal injury in the human brain. These alterations were more marked at longer survival times. Changes in the distribution of the microtubule based proteins were noted in white matter tracts at survival times up to six hours. This morphological appearance may represent an early stage in axonal pathology. The microtubule associated protein, MAP5, was a sensitive marker of injured axons as early as seven hours postsurvival.

Conclusions-Alterations in the cytoskeleton can be detected early in diffuse axonal injury and may reflect cytoskeletal breakdown. These changes progressed with time. Disintegration of the microtubule system interferes with axonal function and could be important in the cascade of events preceding axotomy and irreversible neuronal damage. Early markers of axonal injury permit further investigation of the pathophysiology of white matter damage.

OPTIMISING OXYGEN DELIVERY IN NEUROSURGICAL PATIENTS: ASSESSMENT OF TRANSFUSION REQUIREMENTS

CJ Gerber, P deSouza, A Goringe, CAJ Wardrop, BA Simpson. Departments of Neurosurgery and Haematology, University Hospital of Wales, Cardiff

In the critically ill patient, optimisation of systemic oxygen delivery $\left(\mathrm{DO}_{2}\right)$ improves outcome. $\mathrm{DO}_{2}$ is influenced by both haemoglobin concentration ([Hb]) and blood volume (BV, normal range $70-80 \mathrm{ml} / \mathrm{kg}$ ). [Hb] is a ratio of, and so depends on, the plasma volume (PV) and the total red cells in the circulation-red cell volume (RCV, normal range $20-35 \mathrm{ml} / \mathrm{kg}$ ). Therefore, when $P V$ and RCV fluctuate, [Hb] may not represen accurately the blood oxygen carrying capacity or blood volume (BV). Current blood transfusion practice may fail to optimise $\mathrm{DO}_{2}$ in neurosurgical patients.

RCV and $[\mathrm{Hb}]$ were estimated in a pilot series of 40 patients ( 31 women, nine men) who had a major neurosurgical problem (for example, head injury, subarachnoid haemorrhage, intracranial tumour)

Generally, [Hb] correlated poorly with RCV and BV $\left(r^{2}=0.16, n=40\right)$. In 17 patients with normal $[\mathrm{Hb}]$, both RCV (19.1 $(4 \cdot 7) \mathrm{ml} / \mathrm{kg})$ and BV $(54 \cdot 3(9 \cdot 8) \mathrm{ml} / \mathrm{kg})$ were low.

Clinically unsuspected low BV is common in neurosurgical patients. Reliance on [Hb] may result in suboptimal cerebral oxygenation in these patients. In such patients, RCV estimation gives a more accurate indication of transfusion requirements. [Hb] does not give a measure of RCV or BV.

THE PREDICTION OF DELAYED CEREBRAL ISCHAEMIA USING TRANSCRANIAL DOPPLER SONOGRAPHY AND MEASURING MEAN CEREBRAL TRANSIT TIME

FC Wong, IR Piper, JD Miller, C Stephenson, M Merrick. Department of Neurosurgery, Leeds General Infirmary, Leeds and Department of Clinical Neurosciences, Western General Hospital, Edinburgh, UK

The value of combining transcranial Doppler (TCD) with the measurement of mean cerebral transit time (MCTT) has been investigated with the main aim of predicting delayed cerebral ischaemia (DCI) more accurately.

Patients and method-Patients admitted with a possible diagnosis of aneurysmal SAH 
were monitored. The mean flow velocities of the middle and anterior cerebral arteries (MCA and ACA) were measured. MCA mean flow velocities greater than $120 \mathrm{~cm} / \mathrm{s}$, or ACA/MCA velocity ratio greater than 1.2 were considered abnormal. MCTT had been measured using a technique developed in Edinburgh based on the first pass transit of technetium-99 through the cerebral circulation. MCTT greater than 7.7 seconds (95\% confidence interval lies between 2.5 to $7 \cdot 7$ seconds for normal MCTT) or interhemispheric asymmetry $>1 \mathrm{~s}$ in defined regions of interest were considered abnormal.

Results-Thirty two patients who had both TCD and MCTT studies were suitable for final analysis. Using TCD results alone, TCD predicted 10 out of the 12 patients who subsequently developed DCI, giving it a sensitivity of $83 \%$. However, TCD results were normal in only four out of 20 patients who did not develop DCI, giving it a specificity of only $20 \%$. Its positive and negative predictive values were $38 \%$ and $67 \%$ respectively. When TCD results were combined with MCTT results, the sensitivity and specificity of the combined tests were $67 \%$ and $70 \%$ respectively. Their positive and negative predictive values were $57 \%$ and $78 \%$ respectively.

Conclusions-The prediction of DCI using TCD sonography alone was limited mainly by a very poor specificity. When TCD was combined with the measurement of MCTT, the sensitivity dropped from $83 \%$ to $67 \%$ but the specificity was greatly improved, from $20 \%$ to $70 \%$. The positive and negative predictive values were improved too. Therefore, the addition of MCTT to TCD studies is potentially useful in the prediction of DCI.

REGIONAL AUDIT OF PATIENTS WITH TRANSIENT ISGHAEMIC ATTACKS J Addison, $\mathbf{P}$ Tripathi, O Williams, JD Pickard, PJ Kirkpatrick (on behalf of the East Anglian TIA Audit Group). Academic Neurosurgical Unit, Addenbrooke's Hospital, Cambridge, UK

Introduction-Questionnaires to determine the variation in referral and treatment for patients with TIAs, amaurosis fugax, and those who have made a good recovery from stroke, were distributed to all general practitioners (GPs), consultant physicians, and geriatricians in East Anglia and Bedfordshire. An internal study of patients undergoing surgery between 1993 and 1994 was also carried out to identify reasons for delay in surgery.

Results-(A) Regional study: 1001 (59\%) GP questionnaires were returned. Although $984(98 \%)$ start treatment with aspirin, only $28 \%$ refer after the first TIA (a significant variation between districts was found: $18 \%-41 \%, P<0.01)$. Most $(62 \%)$ refer if the patient has further TIAs, and/or if the patient had a carotid bruit (34\%), and $34 \%$ consider such referrals as urgent. Of the 84 consultant replies, $45 \%$ refer if the patient had further TIAs and/or had a carotid bruit $(20 \%)$, and $52 \%$ refer urgently. (B) Internal study: The median time to surgery $(n=56)$ after onset of symptoms was 124 days. Causes for delay included delay in GP referral (median 90 days), delay in investigations (21 days), and subsequent delay in referral for surgery (seven days).

Conclusion-Recent publication of national guidelines for the management of carotid disease has not been followed by adequate implementation at GP or consultant physician level.

\section{POSTERIOR TRANSARTICULAR SCREW}

FIXATION OF THE UNSTABLE ATLANTOAXIAL

JOINT: EXPERIENCES WITH 54 CASES

ATH Casey, A Madawi, R Veres, HA Crockard. The National Hospital for Neurology and Neurosurgery, Queen Square, London, UK

Objectives-In 1987 Jeanneret and Magerl first described this ingenious method for stabilising the atlantoaxial region. However, this technique is demanding and carries a risk of vertebral artery and spinal cord injury. The question is does the increased stability afforded by this technique justify the potentially high risks involved?

Design - We therefore decided to analyse our own experience with this technique in a cohort of 54 patients (1991-4) in particular examining the operative complications. Radiological evaluation included dynamic cervical spine radiographs, and CT of the atlantoaxial region to assess stability and screw location. If screw position or clinical symptoms were suggestive of vertebral artery injury the patient was further examined by angiography $(n=6)$.

Patients-The mean age of the patients studied was 52.5 (range 19-80). The indications for surgery were classified into those of rheumatoid arthritis $(n=35)$, psoriatic arthropathy $(n=1)$, trauma $(n=13)$, Chiari malformation $(n=2)$, tumour $(n=1)$, infection $(n=1)$, and degenerative $(n=1)$.

Results-Stability of the atlantoaxial region was achieved in $95 \%$ of cases. Injury to the vertebral artery recognised at the time of surgery occurred in three cases. In one case this resulted in a Wallenberg's syndrome. The other two patients were not neurologically compromised. A further patient developed a delayed onset tetraparesis two weeks after surgery; vertebral angiography disclosed an occluded vertebral artery. Four patients $(7.5 \%)$, all with rheumatoid arthritis, had fractured screws which was related to screw malposition, with only unilateral screw purchase achieved. This instrumentation failure occurred within three months of the procedure

Conclusion-This technique has advantages over the existing methods of atlantoaxial fixation, providing stability in $95 \%$. However, enthusiasm for the demanding technique should be tempered by the risks of vertebral artery injury and does not make it a procedure for the occasional operator.

\section{QUANTIFICATION OF CEREBRAL}

HAEMODYNAMIC RESPONSES AFTER INTERNAL CAROTID ARTERY CLAMPING USING NEAR INFRARED SPECTROSCOPY

PJ Kirkpatrick, SA Love, MC O'Kane, D Simpson, P Smielewski, M Czosnyka. University Department of Neurosurgery, Addenbrookes Hospital, Cambridge, UK

Introduction-Near infrared spectroscopy (NIRS) and jugular venous oxygen $\left(\mathrm{SjO}_{2}\right)$ measurements have been used to characterise the cerebral haemodynamic events during carotid endarterectomy

Methods-Forty one patients were monitored with NIRS and transcranial Doppler (FV). In $21 \mathrm{SjO}_{2}$ estimations were made via an ipsilateral jugular catheter. Mean variables were calculated at specific stages of surgery and compared (paired $t$ test). Two patterns of changes in oxyhaemoglobin $\left(\mathrm{HbO}_{2}\right)$ concentration were distinguished: Group $1(n=24)$ patients included those where the fall in $\mathrm{HbO}_{2}$ was small $(<1$ $\mu \mathrm{mol} / \mathrm{l})$ or showed a rapid recovery $(\geqslant$ $50 \%)$ towards baseline after internal carotid (IC) clamping. In group $2(n=17) \mathrm{HbO}_{2}$ signals showed little recovery $(<50 \%)$ or fell further.

Results-In group 1 an increased $\mathrm{HbO}_{2}(\mathrm{P}$ $=0.027)$ and total haemoglobin $(P=0.023)$ concentration was seen after clamp removal which was not seen in group 2. After IC release, the FV pulsatility index was increased above baseline values only in group $1(P=0.0082)$. Analysis of $\mathrm{SjO}_{2}$ changes showed a mean desaturation from 67.8 to $65.5 \%$ after clamping, which increased to $69.8 \%$ after IC release. These differences were significant for right sided catheters only $(P=0.05$ and $P=0.001$ respectively).

Conclusions-NIRS can distinguish changes in cerebral haemodynamics which are not seen with conventional monitoring for carotid surgery.

POSTERIOR LUMBAR INTERBODY FUSION: A NEW TECHNIQUE IN THE MANAGEMENT OF LUMBAR DISC DISEASE

RW Gullan, AT King, GPF Selmon, CC Penney. Department of Neurosurgery, Brook General Hospital, London, UK

Posterior lumbar interbody fusion (PLIF) using the Brantigan carbon cage system is a new technique for the management of degenerative disc disease. Preliminary findings of a pilot study are presented using this system. Eleven patients (nine women, two men) underwent a PLIF procedure for single level lumbar disc disease. The age range was 25-58 (mean 39.3) years. Follow up was between 6 and 18 months (mean 10 months, median 12 months), and over one year in eight patients. All patients had had previous disc surgery on the same level, twice in two cases. Three had gained no relief of symptoms from previous surgery. Of the remaining eight, recurrence of symptoms occurred at between two months and 17 years (median 20 months). All patients had leg and back pain, with back pain being the major complaint in five. Root tension signs were present in 10 patients. In seven patients radiology (MRI or CT myelogram) showed root compression. Leg pain was symptomatically improved after surgery in all 11 patients. However, preliminary findings suggest that although this technique produces radiological fusion, this does not necessarily correlate with improvement in back pain.

CRANIOFACIAL ACCESS TO THE CLIVUS

DA Lang, G Neil-Dwyer, BT Evans. Wessex Neurological Centre, and Department of Oral and Maxillo-facial Surgery, Southampton University Hospitals, Southampton, UK

Of 400 skull base operations using craniofacial access, 54 were done in patients harbouring benign or low grade malignant pathology in the region of the clivus (54 operations in 45 patients). There were 33 women; age range 8-78 years. Most of the tumours were meningiomas $(47 \%)$, chondrosarcomas $(11 \%)$, and chordomas (11\%). A complete excision was achieved in $44 \%$ and a subtotal removal in $44 \%$. The rest had a partial removal $(9 \%)$ or biopsy alone $(2 \%)$. 
Nine patients had postoperative radiotherapy. The mean follow up was 3.5 years (range 6 months-7 years). Overall 33 had a favourable outcome $(73 \%), 5(11 \%)$ were severely disabled, and seven (16\%) died. Whereas surgical expertise had been emphasised in dealing with pathology in this region a holistic approach is advocated, based on the evidence obtained as to the care of these patients. The importance of preoperative preparation/investigation, clear surgical aims and objectives, and the role of biopsy are emphasised. "Rules of access" have been defined and key points underlined when dealing with the pathology, its vascularity, and effecting a safe reconstruction. It is considered that a better outcome for patients depends on the recognition and acknowledgment of complications and the avoidance of a narrow specialist view.

A TECHNIQUE TO PREVENT CSF LEAKAGE AFTER ACOUSTIC NEUROMA SURGERY

NL Dorward, RD Illingworth, AD Cheesman. Regional Neurosciences Centre, Charing Cross Hospital, London, UK

Objective-The evaluation of a new method of meatal closure to prevent CSF rhinorrhoea after retrosigmoid excision of acoustic neuromas.

Design-Operations were performed by a standard posterior fossa approach with drilling of the internal auditory meatus (IAM) by an ENT surgeon. Before 1994 a number of methods had been used to close air cells in the IAM. Since January of 1994 a small patch of superficial fascia, taken from the upper end of the retromastoid incision and held with Histoacryl glue has been used to close the IAM. Retrospective analysis of the incidence of CSF leakage before adopting this method has been compared prospectively with patients treated subsequently.

Patients-Fifty consecutive patients undergoing excision of acoustic neuroma of all sizes from 1990 to 1995 .

Results-Leakage occurred in nine of 23 (39\%) patients before the introduction of the new method. All of these required cortical mastoidectomy and fat implantation to stop the leak. After the introduction of the new method one leak has occurred in 27 $(3.7 \%)$ cases and that settled after a lumbar puncture $(P<0.01)$.

Conclusions-A graft of superficial fascia held with Histoacryl glue is an effective method of closing air cells in the IAM and avoids the need to make a second incision to obtain fascia lata.

GASTROPROTECTION IN NEUROSURGERY: THE PRACTICE IN GREAT BRITAIN

TA Carroll, K Morris, D Rawluk. National Neurosurgical Unit, Beaumont Hospital, Dublin, Ireland

The indications for gastroprotection concurrent with corticosteroid use or as prophylaxis for stress ulceration in the intensive care unit remain unclear. The aim was to determine to what extent gastroprotection is practised in British neurosurgical units. Data were obtained by questionnaire circulated first in 1988 and then in 1994. A return of $76 \%$ and $74 \%$ respectively was obtained. Out of 92 surgeons who replied in 1988,49 routinely used a gastroprotective agent with corticosteroids and 47 with patients at risk of stress ulceration-for example, severely head injured. This compares with 63 out of 89 surgeons using a gastroprotective agent with steroid administration and 60 using prophylaxis for stress ulceration in 1994. The gastroprotective agent of choice in 1988 was an $\mathrm{H}_{2}$ antagonist (76) followed by antacids (36). In 1994, it was again an $\mathrm{H}_{2}$ antagonist (69) but sucralfate (15) was now the second most common agent used. The number of reported peptic ulcer complications (perforation or haemorrhage) among those surgeons who did not routinely use gastroprotective agents was no higher than those who did. Our findings indicate extensive and increasing administration of gastroprotection agents within neurosurgery. The practice of $\mathbf{H}_{2}$ antagonist prescribing in the intensive care unit and the use of gastroprotective agents with corticosteroids may not be warranted.

WIDERANGING IMPROVEMENT AFTER

STEREOTACTIC PALLIDOTOMY (LEKSELL-

LAITINEN OPERATION) FOR PARKINSON'S DISEASE

CHA Meyer. Midland Centre for Neurosurgery and Neurology, Birmingham, UK

Objective-To assess the effects of posteroventral pallidotomy on symptoms of Parkinson's disease.

Design-Stereotactic pallidotomy was performed unilaterally using the Hitchcock stereotactic system. Postoperative brain scanning confirmed the site of the thermolesion. Patients took their established medication both preoperatively and postoperatively.

Outcome measures-Patients were assessed during off and on phases preoperatively and during the week postoperatively by rating scales (for clinical features and UPDRS) and by the time to complete standardised motor tasks testing a wide range of voluntary actions involving individual limbs or the trunk and limbs.

Results-After stereoablation there were statistically significant improvements (sign test) in dyskinesiae, rigidity, resting tremor, and action-postural tremor, improvements in motor freezing, and restoration of automatic arm swinging. There was considerable improvement (Wilcoxon tests) in bradykinesia, especially during off phases, with improvements - some striking - in a wide range of timed motor tasks testing hand and arm actions (unilateral and bilateral), repetitive foot movements, gait and, of particular interest, various actions involving the trunk.

Conclusion-This operation has promise for treating symptoms of Parkinson's disease.

IMPORTANCE OF THE COCHRANE COLLABORATION TO NEUROSURGERY D Simpson, MC O'Kane, PJ Kirkpatrick. Academic Neurosurgical Unit, Addenbrooke's Hospital, Cambridge, UK

Evidence concerning the effectiveness of health care is not readily available to clinicians. Randomised controlled trials (RCTs) are most likely to provide accurate and reliable information. Reports of original research are numerous, hence most clinicians rely on reviews as a means of coping with the increasing volume of information.
The quality of many reviews varies because a systematic approach is not always followed. In particular the control of bias and random error is often overlooked. As a consequence, advice and recommendations on potentially effective forms of care is often delayed.

In response, the NHS Research and Development Programme established the UK Cochrane Centre in Oxford to facilitate and coordinate systematic review of treatments in health care. Their aim is to maintain and disseminate evidence from RCTs through the Cochrane Database of Systematic Reviews. Although considerable contributions have been provided regarding important neurosurgical issues, ${ }^{12}$ several areas in neurosurgery could still bertefit from standardised systematic review. The Cochrane Collaboration has identified 35 such topics. The review group mechanism within the Collaboration provides neurosurgeons with the opportunity of delivering and maintaining effective reviews in chosen areas of neurosurgery.

Anderson R, Meeker WC, Wirick BE, Mootz RD Kirk DH, Adams A A meta-analysis of $\mathrm{RD}$, Kirk DH, Adams A. A meta-analysis of clinical trials of spinal manipulation. Manipulative Physiol Ther 1992;15:181-94.

2 Brown EM. Antimicrobial prophylaxis in neurosurgery. If Antimicrob Chemother 1993;31: (suppl B) 49-63.

THE RELATION BETWEEN IDENTITY

FUNCTIONING AND SEIZURE OUTCOME IN PATIENTS WHO HAVE HAD SURGERY FOR INTRACTABLE EPILEPSY

DA McMackin, T Burke, JP Phillips, H Staunton. Richmond Institute,for Neurology and Neurosurgery, Beaumont Hospital, Dublin, Ireland

Objective-Chronic seizures may impair normal identity development and self evaluation. The objective of this study was to evaluate identity and self image after temporal lobectomy for intractable temporal lobe epilepsy.

Design - The methodology of identity structure analysis (ISA) was employed, which facilitated the development of an epilepsy specific identity instrument. Twenty eight entities comprising significant others and facets of self-image (ideal self) were rated on bipolar constructs representing 16 areas of psychological vulnerability.

Subjects-The instrument was administered to 22 postoperative and eight preoperative temporal lobectomy patients.

Outcome measures-A two way analysis of variance was carried out to examine the relation between seizure status and identity functioning.

Results-Both seizure free and palliative medical outcome groups displayed significantly improved self evaluation although self image was more significantly enhanced in the seizure free group. Those in the palliative outcome group continued to perceive themselves in a "sick role" by contrast with the seizure free group. Those in the preoperative group displayed evidence of a radically declining self image.

Conclusion-These findings suggest that palliative medical outcome after temporal lobectomy may serve to prophylactically arrest a declining self image while leaving many of the psychological features of chronic illness unchanged. 
LONG TERM FOLLOW UP OF PATIENTS WITH EPILEPSY AFTER MODIFIED ANATOMICAL HEMISPHERECTOMY

V Papanastassiou, Z Zaiwalla, SM Oxbury, J Oxbury, CBT Adams. Department of Neurological Surgery, The Radcliffe Infirmary, Woodstock Road, Oxford, UK

Anatomical hemispherectomy had been described as the best procedure for epilepsy control, but was abandoned in the 1960 s due to the unacceptably high rate of long term complications. In 1980 , the operation was modified in Oxford ${ }^{1}$ and since then some 45 patients have undergone this procedure for intractable, drug resistant, hemiplegic epilepsy. Long term outcome data in 23 of these patients, operated on between 1981 and 1990, is presented. Their average age at the time of surgery was 10.9 (range $2 \cdot 5$ to $18 \cdot 5$ ) years. There were 13 boys and 10 girls, with abnormality on the right in 12 and on the left in 11. There was no mortality. The pathological diagnosis included perinatal brain injury (10), cortical dysplasia (four), Rasmussen's syndrome (three), postencephalitis (three), Sturge-Weber (two), and infarction after embolus (one). The average follow up period is 5.4 (range 1 to 12) years, and 18 patients are now free of epilepsy $(78.3 \%)$, including 10 off medication. Three patients have had a significant $(>75 \%)$ reduction in seizure frequency $(13.0 \%)$, and two patients failed to improve $(8 \cdot 7 \%)$.

1 Adams CBT. Hemispherectomy-a modification. I Neurol Neurosurg Psychiatry 1983; 46:617-9.

OUTCOME AFTER TEMPORAL LOBE SURGERY FOR INTRACTABLE EPILEPSY IN THE PAEDIATRIC AGE GROUP

D Peterson, JH Cross, B Harding, BG Neville, WFJ Harkness. Great Ormond Street Hospital for Sick Children, London, UK

Results are presented for temporal lobe surgery for medically refractory seizure control in 20 patients with a mean age of 12.4 years, performed between 1992 and 1994 . Patients were assessed preoperatively in accordance with an investigation protocol including neurological, neurosurgical, psychiatric, and psychometric opinions in addition to MRI, EEG, and SPECT. Various diseases were encountered including dysembryoblastic neuroectodermal tumour (seven), hippocampal sclerosis (seven), and low grade glioma (two) in addition to tuberose sclerosis, cortical dysplasia, Rasmussen's encephalitis, and hamartoma (one each).

Mean follow up of 21 (range 13-38) months was achieved. All patients benefited from surgery in terms of seizure control, 16 patients became free of disabling seizures (Engel grade I). The remaining four patients experienced greater than $75 \%$ benefit in seizure control. All patients had improved developmental and psychosocial scores.

In medically refractory epilepsy occurring in childhood, temporal lobe surgery may provide excellent seizure control with demonstrated benefit in neurodevelopmental outcome. These results compare favourably with those seen in adult series and reinforce the strategy of early surgical intervention.
RESULTS OF TEMPORAL LOBE RESECTION FOR EPILEPSY IN PATIENTS WITH A PREOPERATIVE MRI DIAGNOSIS OF HIPPOCAMPAL SCLEROSIS OR FOREIGN TISSUE LESION

BC Lopez, WFJ Harkness, J Duncan, D Fish, S Shorvon, A Harding. The National Hospital for Neurology and Neurosurgery, Queen Square, London, UK

The two year outcome after temporal lobe resection for epilepsy is presented for 40 patients operated on in the National Hospital between October 1991 and October 1993.

A preoperative diagnosis of low grade neoplasia or hippocampal sclerosis was made by means of non-invasive tests including neuropsychometry, scalp electroencephalography, and MRI. The diagnosis was confirmed at operation in all cases.

In nine patients $(22.5 \%)$ the diagnosis was of dysembryoplastic neuroepithelial tumour $(8-20 \%)$ or ganglioma $(1-2 \cdot 5 \%)$ with no side predominance. There were five women (55\%) and four men (45\%), with an average age of 27 (range 23-38). Hippocampal sclerosis was diagnosed in 31 patients $(77 \cdot 5 \%), 20$ women $(64.5 \%)$ with a mean age of 28 years (range 20-46) and 11 men $(35.5 \%)$ with a mean age of 31 (range 26-44). Right sided operations were predominant in the women (12 right $v$ eight left), whereas in men left sided procedures prevailed (seven left $v$ four right).

All patients have been followed up for a period of at least 24 (mean 32; range 24-46) months. In the neoplasm group the overall seizure free rate was $66 \cdot 7 \%(60 \%$ of women and $75 \%$ of men). The outcome was slightly better in the hippocampal sclerosis group, in which $74 \%$ of patients were seizure free ( $75 \%$ of women and $72 \%$ of men). In this group the outcome was better for left sided lesions $(80 \%$ left $v 68.5 \%$ right seizure free). Overall, $72.5 \%$ of patients have remained seizure free, half of them with their medication reduced or stopped. The results were critically analysed using Engel's classification.

NEUROSURGICAL TREATMENT OF HYPOTHALAMIC HAMARTOMA CAUSING GELASTIC EPILEPSY

PK Doshi, CE Polkey, P Bullock. The Maudsley Hospital, Denmark Hill, London, UK

Three patients, all boys, with gelastic seizures caused by hypothalamic hamartoma, were treated by surgery. The mean age at the time of treatment was nine (range 4-11) years. In one case the hamartoma was pedunculated and attached to the tuber cinerium and in the other two they were sessile with a broad base and attached to the hypothalamus. A frontotemporal approach was used. The pole and a part of anterior temporal lobe were resected in one case to improve the exposure. The hamartoma was completely excised in one patient and subtotally excised in the other two. Postoperatively all three patients had a varying degree of third nerve palsy. At the time of follow up (mean 9; range 4-18 months) two patients had good seizure control (Engel grade II) and one had some reduction in the severity and frequency of seizures. It is considered that the surgical excision of hypothalamic hamartoma causing gelastic epilepsy is possible and should be considered in all medically intractable cases.
ENDOVASCULAR OCCLUSION OF MIDDLE CEREBRAL ARTERY: TREATMENT OF INTRACTABLE EPILEPSY BY MINIMAL INVASIVE TECHNOLOGY

JP Phillips, J Toland, P Brennan, DA McMackin, H Staunton. Department of Neurology and Neurosurgery, Beaumont Hospital, Dublin, Ireland

A 22 year old woman was referred for surgery because of intractable epilepsy. She presented with cerebral palsy, mild mental handicap, and a mild right hemiparesis. Her seizure disorder began at age four. Throughout her childhood and adolescence she had frequent tonic clonic seizures involving all four limbs with postictal drowsiness occurring at least five times per week. She also suffered partial seizures occurring on a daily basis. Telemetry confirmed the presence of a left hemisphere epileptogenic source but without specific localisation. Brain MRI demonstrated a hemiatrophy involving the left cerebral hemisphere with a porencephalic cyst in the distribution of the left middle cerebral artery. Cerebral angiography demonstrated impaired circulation with revascularisation in the middle cerebral territory. Her visual fields were full.

She was ambulatory with retained function in her right lower limb. She had a claw hand with reasonable proximal movement of her right forelimb. Rather than carry out a functional hemispherectomy with the disadvantage of a homonymous hemianopia it was elected to test the hypothesis that complete devascularisation of the revascularised middle cerebral territory might reduce the volume of epileptogenic cortex and reduce seizure frequency and severity.

The right femoral artery was cannulated and a detachable balloon catheter passed distally without difficulty into the left internal carotid artery. A $3 \mathrm{~mm}$ balloon was placed in position at the bifurcation of the left internal carotid artery and expanded with saline. Proprophrol anaesthesia was utilised. Anaesthesia was reversed and a psychometric assessment performed. Neurological examination was unchanged. There was no speech or memory or cognitive deficit. The balloon position was confirmed and detached from the delivery catheter.

She underwent telemetry after the endovascular procedure. She had two seizures in the first 10 days after operation. She had several minor partial seizures which did not develop. Telemetry showed occasional spike activity now localised to the left frontal region only. There was a $75 \%$ reduction in seizure frequency in the postoperative three month follow up. Endovascular coil obliteration of the residual frontal circulation is being considered.

COST-BENEFIT ANALYSIS IN EPILEPSY SURGERY

PO Byrne, AR Walsh. Department of Neurosurgery, Queen Elizabeth Hospital, Birmingham, UK

Objective-To determine the cost of quality adjusted life years (QALYs), after surgery for epilepsy.

Subjects - Twenty patients, age range 14 to 55 , mean $28 \cdot 15$ years, were operated on between June 1991 and September 1993, giving follow up of 12 to 40 months, average 26.4 months. Nine patients were classified as Engel grade I, "seizure free", four 
patients as grade II, "almost seizure free", three patients as grade III, having a "worthwhile improvement", and four patients as grade IV, "no worthwhile improvement".

Results-For the purposes of this analysis Engel grade I was given a QALY value of $0 \cdot 8$, grade II a QALY of $0 \cdot 65$, Grade III a QALY of 0.3 , and Grade IV a QALY of 0.0 . Using 1994/5 budget prices, a charge of $£ 7957.40$ per operation can be calculated, using total costs for the whole programme and a flow chart of assessment of patients from initial consultation all the way to resectional surgery. Estimated life expectancy to, say, 72 years gave an average of 43.85 years in this population; there were a total of 10.7 QALYs derived from the treatment of the population. The total cost, $£ 7957 \cdot 40$, divided by the QALYs-namely, $10.7 \times 43.85$, equalling 470.08 QALYs, gives the cost per QALY of $£ 338 \cdot 00$. This figure can be compared with league tables to assess other health care costs. ${ }^{12}$

1 Maynard A. Developing the health care market. The Economic fournal 1991;101: market.

2 Pickard JD, Bailey S, Sanderson H, Rees M, Garfield JS. Steps towards cost-benefit analysis of regional neurosurgical care. $B M \mathcal{F}$ 1990;301:629-35.

ENDOSCOPICALLY ASSISTED VENTRICULAR CATHETER INSERTION: COMPARISON WITH CONVENTIONAL BLIND TECHNIQUE

GA Roberts, D Oluoch-Olunya, C Pidgeon. Beaumont Hospital, Dublin, Ireland

An endoscopically assisted technique for catheter tip placement into the anterior horn of the lateral ventricle has been developed. A cohort of patients having had ventricular catheters inserted with endoscopic assistance for the purposes of ventriculoperitoneal shunting, external ventricular drainage, and intraventricular intracranial pressure monitoring were compared with an equivalent number of retrospective matched controls and differences in terms of length of operation, postoperative CT appearance, early complications, and cost implications were identified.

FACTORS AFFECTING OUTCOME OF STEREOTACTIC RADIOSURGERY (LINEAR ACCELERATOR) FOR CEREBRAL ARTERIO VENOUS MALFORMATIONS

E Nenji, DA Yates, CHA Meyer. Midland Centre for Neurosurgery and Neurology, Birmingham, UK

Design-During 1987-93, 63 patients had cerebral vascular malformations (AVMs) treated by stereotactic radiosurgery using the Hitchcock frame: localisation by orthogonal biplanar stereoscopic paired angiograms, radiosurgical planning with $\mathrm{CT}$ giving six non-coplanar cranial slices, and treatment by linear accelerator. Follow up was annually by cerebral angiography. Changes in radiotherapy policy meant that reduced doses of radiation were given to patients treated in the midportion of the study period.

Patients-Forty five patients with a single AVM treated by single fraction radiosurgery, with follow up for two years or more. Lesion diameters: large (over $2.5 \mathrm{cms}$ ) 20 , medium 12 , small (1 cm or less) 13. Central dose below 2500 cGy in 23 patients; edge dose below $1000 \mathrm{cGy}$ in 17 .

Outcome measures-Obliteration or reduction of AVMs on follow up angiograms.

Results - Radiographic outcome (obliterated, reduced, unchanged) at one year was $10 \%, 43 \%, 47 \%$; at two years $38 \%, 27 \%$, $35 \%$-with no improvement thereafter. Outcome was significantly poorer $\left(\chi^{2}\right.$, Fisher exact probability test) if the AVMs were large, had a high flow rate, poor edge demarcation, irregular shape, central dose 3000 cGy or less, edge dose below 1500 cGy, and if targeting failed to cover the AVM completely.

Conclusion-This technique can obliterate AVMs especially if lesions are small, spherical, and totally encompassed by radiosurgery with an edge dose of at least 1500 cGy.

AUDIT OF THE MEDOS PROGRAMMABLE SHUNT: OUTCOME AT TWO YEARS

A Kay for UK Medos Shunt Audit Group. Academic Neurosurgical Unit, Box 167, Addenbrooke's Hospital, Cambridge, UK

Objective-Evaluation of outcome two years after insertion of a Medos programmable valve for complex hydrocephalus.

Method-Multicentre audit study.

Setting-Smethwick, Cambridge, Maudsley, Southampton, Wakefield, Leeds, Sheffield, Royal London, St Bartholomews, Newcastle, Coventry, Belfast, Plymouth and Dublin.

Results - Of the 148 valves inserted in 139 patients, 28 (18.9\%) have been removed: 21 (14\%) due to infection; four $(2 \cdot 7 \%)$ due to shunt malfunction; two LP shunts due to programming difficulty; one due to ventricular catheter disconnection. There were 13 $(\mathbf{8} \cdot \mathbf{8} \%)$ shunt revisions. Subdural collections were detected in $35(23.6 \%)$ patients. Of the 22 symptomatic collections, seven required evacuation and nine resolved at a higher program pressure. The mean adult Evans ratio before shunting was $0.3(n=71)$ and $0.21(n=25), 0.20(n=21)$ and $0.19(n=$ 12) at 6,18 , and 24 month follow up respectively. The programming facility proved useful in the control of headache persisting after shunting. Outcome (Glasgow outcome score) was good in $63(52 \%)$, moderate in $31(26 \%)$, severe in $17(14 \%)$, PVS (0\%), 19 (15\%) died. Twenty seven $(22 \%)$ patients had been discharged to the care of their general practitioner at last follow up.

Conclusion-There is a learning curve for the use of this valve but it facilitates the management of complex hydrocephalus.

EARLY EXPERIENCE WITH CHRONIC ELECTRICAL STIMULATION OF THE THALAMUS FOR THE CONTROL OF TREMOR TRK Varma, A Forster, $R$ Roberts. Departments of Neurosurgery, Neurophysiology, and Neurology, Dundee Royal Infirmary, Dundee, UK

Objective-To evaluate experience with chronic thalamic stimulation which has been shown to be effective in the control of tremor refractory to medical treatment. ${ }^{1}$

Design-A review of patients with tremor who underwent surgery for the placement of thalamic stimulators.

Subjects-Five thalamic stimulators were placed in four patients (one bilateral) using a two-stage stereotactic procedure with MRI localisation and multimodel neurophysiological studies. All patients had chronic tremor due to Parkinson's disease or benign essential tremor.

Outcome measures-Tremor control was evaluated using tremor analysis, video recordings, and the unified Parkinsonism rating scale or the essential tremor rating scale. Complications and side effects were noted.

Results-Three of the four patients had abolition of the tremor during stimulation with no side effects or complications. One patient had a microthalamotomy effect with subsequent electrode migration.

Conclusions-Chronic electrical stimulation of the thalamus offers effective control of drug refractory tremor and avoids the potential hazards of thalamotomy.

1 Benabid AL, Pollak P, Gervason C. Long term suppression of tremor by chronic stimulation of the ventral intermediate thalamic nucleus. Lancet 1991;337:403-6.

MEDIAL PALLIDOTOMY FOR DRUG INDUCED DYSKINESIA AND RIGIDITY USING IMAGE FUSION AND STEREOPLAN

T Aziz, J Rowe, V Papanastassiou. Department of Neurological Surgery, The Radcliffe Infirmary, Woodstock Road, Oxford, UK

Present day understanding of the neural mechanisms underlying Parkinson's disease, would suggest that a precisely placed lesion in the medial pallidum should alleviate the symptoms of rigidity, akinesia, drug induced dyskinesia, and possibly tremor. ${ }^{1}$ Such a lesion needs to be placed with extreme accuracy, as encroachment on to the lateral pallidum will result in exacerbation rather than relief of symptomatology. In addition, extension into the internal capsule or optic radiation would result in significant neurological deficit. To place such lesions, surgeons would normally extrapolate from the intercommissural (AC-PC) line, $20 \mathrm{~mm}$ lateral, 2-4 $\mathrm{mm}$ anterior, and $3-6 \mathrm{~mm}$ inferior to the midcommissural point. ${ }^{2}$ Final localisation would depend on intraoperative recording. We report the first ever use of the Radionics Stereoplan system with image fusion to perform this procedure. The direct calculation of target coordinates using Stereoplan and MRI/CT image fusion resulted in greatly increased accuracy compared with the traditional method, confirmed on postoperative MRI, with excellent clinical results and significant reduction in operating time.

1 Aziz TZ, Peggs D, Agarwal E, Sambrook MA, Crossman AR. Subthalamic nucleotomy alleviates parkinsonism in the 1-methyl-4phenyl-1,2,3,6-tetrahydropyridine (MPTP) exposed primate. $B r \quad \mathcal{F}$ Neurosurg 1992;6: 575-82.

2 Laitinen LV, Bergenheim AT, Hariz MI Leksell's posteroventral pallidotomy in the treatment of Parkinson's disease. $\mathcal{F}$ Neurosurg 1992;76:53-61.

USE OF IMAGE FUSION AND THE RADIONICS OPERATING ARM SYSTEM FOR IMAGE GUIDED NEUROSURGERY

V Papanastassiou, J Rowe, T Aziz. Department of Neurological Surgery, The Radcliffe Infirmary, Woodstock Road, Oxford, UK

The first ever use of image fusion and the Radionics Operating Arm System (OAS) for 
image guided neurosurgery (IGN) is reported. Both CT and MR images have been used separately for IGN and frame based stereotactic procedures. ${ }^{1}$ The consensus of opinion is that, whereas MRI provides unsurpassed anatomical detail, it cannot match the three dimensional accuracy of CT. ${ }^{2}$ The problem becomes particularly important in functional neurosurgery and for lesions that are deep seated and not detectable with CT. This new technique allows MR images to be matched to the CT bone contour and thus retain the advantages of both imaging modalities. Seven cases with diverse pathologoanatomical characteristics have highlighted the accuracy of the fusion process, the ease of use, and the operative benefits of combining detail and accuracy.

1 Sandeman DR, Patel N, Chandler C, Nelson RJ, Coakham HB, Griffith HB. Advances in image-directed neurosurgery: preliminary compared with the Leksell $\mathrm{G}$ frame. $B r f$ compared with the Leksel
Neurosurg 1994;8:529-44.

2 Sumanaweera TS, Adler JR, Napel S, Glover GH. Characterization of spatial distortion in magnetic resonance imaging and its implications for stereotactic surgery. Neurosurgery 1994;35:696-704.

ACCURACY OF CONTOUR MAP REGISTRATION WITH THE ISG VIEWING WAND IN ROUTINE CLINICAL PRACTICE

C Bolger, P Byrne, PR Eldridge, MDM Shaw. Walton Hospital, Rice Lane, Liverpool, UK

Objective-To investigate the "on the table" accuracy of the ISG viewing wand when used as a routine tool in everyday neurosurgical practice by all surgeons within the department. Only one surgeon had formal training in the use of the wand.

Design-Patients were CT scanned (slice thickness $3 \mathrm{~mm}$ ) with three fiducial markers in place before surgery. The patient was registered to the wand with contour mapping, without reference to the fiducials, by the operating surgeon. Accuracy of registration was checked independently by measuring the difference between the true and wand predicted fiducial position.

Subjects-To date 18 subjects (registrations) from six surgeons have been evaluated.

Outcome measures-Difference in true and wand predicted positions of three surface fiducials.

Results-The mean (SD) difference between true fiducial position and wand predicted fiducial position in this study was $3 \cdot 4$
(2) $\mathrm{mm}$. There was a wide range of accuracy from 1 to $8.5 \mathrm{~mm}$. Most of the variation was associated with one surgeon and if these three patients are excluded the mean difference was $2.6(1) \mathrm{mm}$.

Conclusions-These results support the use of the ISG viewing wand as an aid to general neurosurgical practice, particularly for surgeons without an interest or training in formal stereotaxy. However, whereas accuracy levels of $1 \mathrm{~mm}$ are obtainable, the wand should not universally be applied as a replacement for currently performed stereotactic procedures. Variation between surgeons emphasises the need for accuracy checks before embarking on surgical intervention.

FRAME BASED IMAGE GUIDED STEREOTACTIC PROCEDURES FOR MASS LESIONS

MS Sankhe, TRK Varma. Department of Neurosurgery, Dundee Royal Infirmary, Dundee, UK

Objective-To study the pathological yield rate, histological diagnosis, and complications of stereotactic surgery for mass lesions.

Design-Retrospective analysis of operative details, histology, and complications of 109 stereotactic procedures.

Patients-One hundred and two patients aged 4 to 77 years underwent stereotactic procedures for mass lesions.

Outcome measures-Histological confirmation of diagnosis, identification of technica problems and evaluation of complications.

Results-There were 109 procedures in 102 patients, with $76(69 \cdot 7 \%)$ biopsies and $30(27 \cdot 5 \%)$ excisional procedures. There were six infratentorial lesions, and one patient underwent an abscess drainage, cannulation, and localisation. There were 101 $(92.6 \%)$ procedures done under CT guidance and eight $(7 \cdot 3 \%)$ under MRI guidance. A positive histological diagnosis was obtained in all except four procedures, only one patient had neurological deterioration after the procedure, and one immunocompromised patient died perioperatively due to fulminant meningitis.

Conclusions-The stereotactic procedures for mass lesions have a high reliability with a low morbidity.

1 Arbit E, Galicich JH. Importance of image guided stereotactic biopsy to confirm diagnosis in an oncological setting. Ann Surg Onco 1994;1:368-72.

2 Tasker RR. State of the art reviews. Neurosurgery 1987;2:165-91.
EVALUATION OF VISLAN, A NEW STEREOVIDEO BASED SYSTEM FOR PREOPERATIVE PLANNING AND INTRAOPERATIVE GUIDANCE AJ Strong, ACF Colchester, RE Evans, J Zhao, CJ Henri, DGT Thomas, P Roberts, N Maitland. Maudsley, Guy's, and National Hospitals, London, UK and Roke Manor Research Ltd, UK

Objectives-Current intraoperative image based guidance systems rely on mechanical position sensing and are not ideal for use in conjunction with the operating microscope. Alternative systems based on optical detection of position are being developed by several groups: most systems use specialised cameras to detect infrared LEDs.

Methods-We have developed a more versatile system where passive illumination is used with a pair of standard video cameras with three functions. (1) The three dimensional shape of a part of a patient's face or scalp is reconstructed, and is used to provide an initial registration with preoperative image data. (2) Markers which are attached to the patient around the craniotomy, or alternatively to the Mayfield clamp, are localised by the system and used to update registration if patient movement occurs. (3) $A$ hand held surgical pointer without connecting cables is tracked in real time. The complete VISual LANdmark system includes software for segmenting, registering and displaying structures in preoperative images, as well as for merging these with intraoperative video images.

Results-After test shifts between two surfaces of $\pm 5 \mathrm{~mm}$ and $\pm 10^{\circ}$ the system was able to reregister to $0.5(\mathrm{SD} 0.3) \mathrm{mm}$ and $0.3(0.3)$ degrees. During stereo-video reconstruction of a surface obtained from patterned light, the SD of deviation of calculated points from the flat plane was $\pm 0 \cdot 15$ $\mathrm{mm}$. The system has been evaluated in four patients undergoing surgery for glioma, and in one patient with an acoustic neuroma. Registration and verification in theatre may require as little as 20 minutes. Surgical utility in respect of convenience, speed of response and compatibility with the operating microscope was very considerable.

Conclusions-Initial experience of this system is highly encouraging, although modifications to the target capture routine are required to reduce its vulnerability to adverse lighting conditions. In addition to use in theatre, the preoperative facilities in the system may have significant potential as an aid to neurosurgical training and education. 